\title{
Hydration of Formaldehyde in Water: Insight from ONIOM Study
}

\author{
Hui Zhang and Chan Kyung Kim* \\ Department of Chemistry, Inha University, Incheon 402-751, Korea. "E-mail: kckyung@inha.ac.kr \\ Received October 21,2008
}

Key Words : ONIOM, Solvent effect, Iydration of formaldehyde, Cooperative mechanism

The theoretical representation of solvent effects in studying reaction mechanisms and rates in condensed phases is an important but a difficult problem in chemical physics.' The neutral hydration of carbonyl group is commonly thought to proceed via a stepwise pathway with charged intermediates in water solvent. ${ }^{2}$ However, this mechanism is disfavored due to continuous solvation and desolvation of reaction species with respect to a cyclic, cooperative mechanism (Scheme I), as originally suggested by Eigen ${ }^{3}$ and by Long. The neutral hydration of a carbonyl group by a cooperative mechanism involving several water molecules implies the formation of a cyclic $n$-membered reaction complex, and protons moving, more or less synchronously, in the transition state. This suggestion was supported and taken up theoretically ${ }^{3}$ and experimentally. ${ }^{6}$

With an assumption that the water clusters $\left(\mathrm{H}_{2} \mathrm{O}\right)_{n}$ are in rapid equilibrium with each other and with the reactant complexes $\mathrm{RC}_{\mathrm{n}}$, the neutral hydration of formaldehyde was theoretically found to involve four water molecules in the gas phase and in water. But the experimental works gave inconsistent results for the mechanism - three water molecules involving, ${ }^{7}$ or four water molecules involving cooperative mechanism ${ }^{5}$ without catalyst.

One possible reason for the discrepancy between the theory and experiment might be that both works were unable to consider the water-assisted effect ${ }^{\gamma}$ in the gas phase and the solvent effect accompanied by the water-assisted effect in water, and it is obvious that the water-assisted effect is more important in water than in the gas phase since there are lots of available water molecules surrounding the reaction system.

In this work, hydration of formaldehyde is reexamined in detail by micro-solvation which divides the role of water molecules into three parts - directly involved in the reaction (called active water molecules), in the first and second solvation shells. Especially, the model system selected in this work is the hydration of formaldehyde by two water molecules, 1 ( $n=2$ in Scheme I). In considering the first solvation shell, solvent water molecules could be positioned around the three regions as shown in Scheme 2. Region 1 relates to the interaction of ancillary water molecules with two hydrogens of formaldehyde, region 2 relates to the interaction with carbonyl oxygen, and region 3 relates to the interaction with active water molecules. Final mode] was generated after adding additional water molecules in the second solvation shell under the constraint of water density of $1.0 \mathrm{~g} / \mathrm{cm}^{3}$, which was calculated from the Connolly volume surface by using MS Modeling software. ${ }^{10}$

The calculations started by gradually adding a series of water, $\mathrm{nH}_{2} \mathrm{O}(\mathrm{n}=0,2,3,5,6,20)$ around the reaction system. Energies for the reactant complexes (RCs), transition states (TSs), product complexes (PCs), activation energies and reaction energies are summarized in Table 1 . As the number of water molecules in the first solvation increased, activation and reaction energies showed similar concave pattem - activation and reaction energies show minima when $n=3$ and 5 , respectively. Here we chose $n=5$ as the first solvation shell model, which was employed to generate the final model. This was because the reaction energy showed minimum value at $n=5$ and activation energy could be improved by considering the second solvation. In this model, two orientations of five ancillary water molecules were found to be possible as shown in Figures 1 and 2. (1) Model I (labeled M1): four of them were located near the active water molecules and the remaining one near to the carbonyl oxygen, (2) Model 2 (labeled M2): three ancillary water molecules were linked to the active water molecules and two others to the carbonyl oxygen and hydrogen, respectively. These models were further developed to construct the

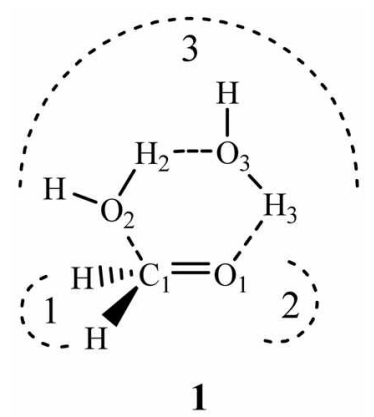

Scheme 2

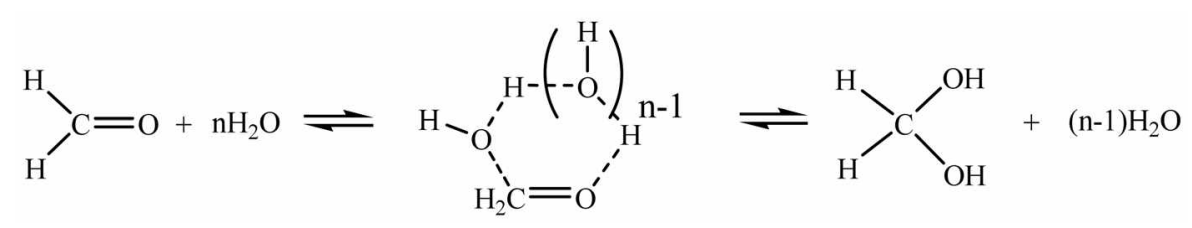


Table 1. Effects of number of water molccules ( $n$ ) in the first solvation shell

\begin{tabular}{rrrrrr}
\hline $\mathrm{n}$ & $\mathrm{E}(\mathrm{RC})^{\circ}$ & $\mathrm{E}(\mathrm{TS})^{\prime \prime}$ & \multicolumn{1}{c}{$\mathrm{E}(\mathrm{PC})^{\prime \prime}$} & \multicolumn{1}{c}{$\Delta E^{\dot{c} \delta}$} & \multicolumn{1}{c}{$\Delta E^{c}$} \\
\hline 0 & -267.37862 & -267.34138 & -267.39057 & 23.37 & -7.50 \\
2 & -418.66875 & -418.64627 & -418.68241 & 14.11 & -8.57 \\
3 & -494.31076 & -494.29566 & -494.32948 & 9.48 & -11.75 \\
5 & -645.59036 & -645.57393 & -645.61508 & 10.31 & -15.51 \\
6 & -721.23480 & -721.21014 & -721.25238 & 15.48 & -11.03 \\
20 & -1780.27977 & -1780.24469 & -1780.28568 & 22.01 & -3.71 \\
\hline
\end{tabular}

"electronic energy in a.u. "activation energy in $\mathrm{kcal} / \mathrm{mol}$. "reaction energy in $\mathrm{kcal} / \mathrm{mol}$

final models by measuring the density of water box using MS Modeling software. We found that 59 water box which had a dimension of approximately $12.3 \AA \times 12.3 \AA \times 12.3 \AA$ satisfied the density criterion. The final models labeled M1f and M2f are also depicted in Figures $I$ and 2 . In the final models, inner layer was composed of the reaction system and five water molecules in the first solvation shell. The rest of the system formed the outer layer, which was treated at the low level of theory. ONIOM optimized energies for the structures considered in this work are summarized in Table 2 .

In the transition states, $\mathrm{O}_{2}-\mathrm{H}_{2}$ and $\mathrm{O}_{3}-\mathrm{H}_{3}$ were broken partially to transfer hydrogen atoms to the neighboring oxygen atoms, which made the TSs polar. Therefore, surrounding solvent could stabilize the TSs by a favorable dipole-dipole interaction or hydrogen bonds. To maximize the polarity of the transition states, $\mathrm{d}\left(\mathrm{C}_{1}=\mathrm{O}_{1}\right)$ became longer and $\mathrm{d}\left(\mathrm{C}_{1}-\mathrm{O}_{2}\right)$ became shorter in M1-TS (and M2-TS) compared to 1 . As a result of such structural changes, the charge density on carbonyl oxygen $O_{1}$ should increase. This implied much stronger interaction of $\mathrm{O}_{1}$ with $\mathrm{H}_{3}$ in the active water. However, $\mathrm{d}\left(\mathrm{O}_{1}-\mathrm{H}_{3}\right)$ increased on going from 1 to M1TS (and M2-TS). This was because there was one freely moving water molecule which could form stronger hydrogen bond to $\mathrm{O}_{1}$. In fact, (hydrogen) bond length between $\mathrm{O}_{1}$ and

Table 2. Energetics (in $\mathrm{kcal} / \mathrm{mol}$ ) for the reaction system studied in this work

\begin{tabular}{ccccc}
\hline Species & $\Delta E_{Z P E}^{\neq}$ & $\Delta E_{\text {miodel }}^{\text {htigh }}$ & $\Delta E^{\text {ONOMF }}$ & $\Delta G^{+}$ \\
\hline 1 & 21.82 & - & - & 23.65 \\
M1 & 14.16 & 20.43 & 14.52 & 16.23 \\
M1f & 13.94 & 18.31 & 14.56 & 17.26 \\
M2 & 16.46 & 21.60 & 16.95 & 18.53 \\
M2f & 14.29 & 17.84 & 15.02 & 15.98 \\
Experimental $^{1,15}$ & & & & 16.00 \\
\hline
\end{tabular}

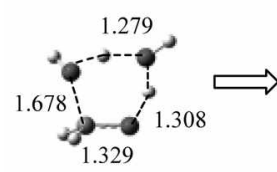

1-TS

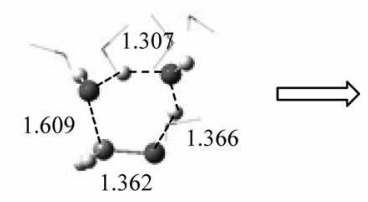

M1-TS

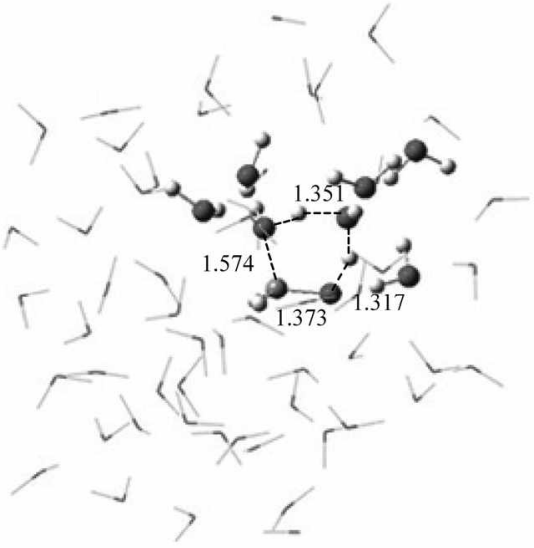

M1f-TS

Figure 1. Transition structures of 1, M1 and M1f. Inner layer is shown in ball-and-stick and outer layer in wireframe.

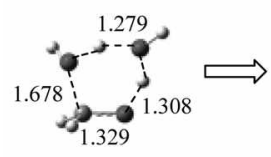

1-TS

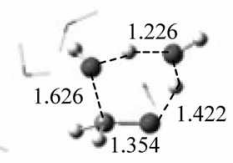

M2-TS

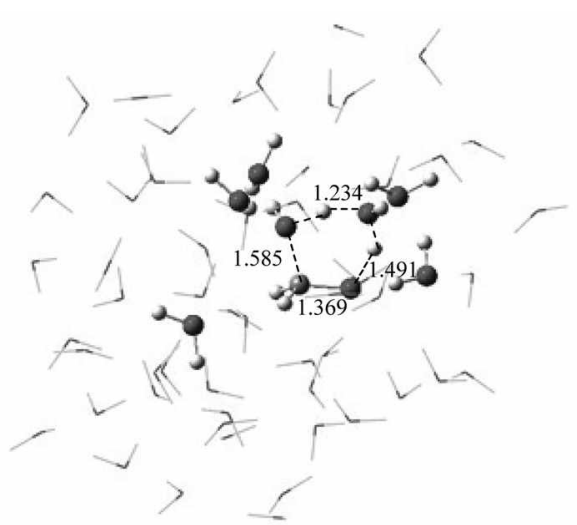

M2f-TS

Figure 2. Transition structures of $1, \mathbf{M} 2$ and M2f. Inner layer is shown in ball-and-stick and outer layer in wirefranc. 
nearby solvent $\mathrm{H}-\mathrm{OH}$ changed from $1.81 \AA$ in M1-RC (and M2-RC) to $1.77 \AA$ in M1-TS (and M2-TS).

Such geometrical changes were reflected in the $\Delta E^{i m}$ values of -5.91 and $-4.65 \mathrm{kcal} / \mathrm{mol}$ for $\mathbf{M 1}$ and $\mathrm{M} 2$, respectively, calculated from Table 2. These amounted to more than $20 \%$ decrease in the activation energies when the first solvation shell was taken into account.

When additional 59 water molecules were added to the reaction system to form the second solvation shell, changes in the geometries and activation barriers could also occur. Similar changes in $\mathrm{d}\left(\mathrm{C}_{1}=\mathrm{O}_{1}\right)$ and $\mathrm{d}\left(\mathrm{C}_{1}-\mathrm{O}_{2}\right)$ were observed: $\mathrm{d}\left(\mathrm{C}_{1}=\mathrm{O}_{1}\right)$ increased continuously $(\mathbf{1}: 1.329 \AA$, M1-TS: 1.362 $\AA$, M1f-TS: $1.373 \AA$, and M2-TS: $1.354 \AA$, M2f-TS: 1.369 $\AA$ ) and $d\left(\mathrm{C}_{1}-\mathrm{O}_{2}\right)$ decreased in a similar pattern. However, $\mathrm{d}\left(\mathrm{O}_{1}-\mathrm{H}_{3}\right)$ showed different behavior. In $\mathrm{M1}$ reaction, $\mathrm{d}\left(\mathrm{O}_{1}-\right.$ $\mathrm{H}_{3}$ ) lengthened from $1.308 \AA$ (1) to $1.366 \AA$ (M1-TS) but decreased to $1.317 \AA$ (M1f-TS). In M2 reaction, however, $\mathrm{d}\left(\mathrm{O}_{1}-\mathrm{H}_{3}\right)$ increased continuously from $1.308 \AA(1)$ to 1.422 $\AA$ (M2-TS) and to $1.491 \AA$ (M2f-TS). Based on these structural variation, we thought that the M2 was better than M1. From Table 2, we calculated the $\Delta E^{\text {int }}$ values to be -3.75 and $-2.82 \mathrm{kcal} / \mathrm{mol}$ for M1f and M2f, respectively, which was over $60 \%$ of the $\Delta E^{i n t}$ values for the corresponding M1 and M2. This suggested that inclusion of the second solvation shell was essential to understand the chemical reactions in solution even if much larger stabilization came from the first solvation shell. This idea was further supported by the comparison of the activation free energies. The $\Delta G^{+}$value for $\mathbf{M} 2 \mathrm{f}$ was $15.98 \mathrm{kcal} / \mathrm{mol}$, in complete agreement with the experimental value of $16.00 \mathrm{kcal} / \mathrm{mol}$.

In conclusion, we have developed two different solvation models on the hydration of formaldehyde catalyzed by two water molecules in aqueous solution. When the solvent effects were considered by using the two-layer ONIOM method, $60 \%$ of the solvation energy came from the first solvation shell and the rest from the second solvation shell. Our activation free energy calculated using M2 matched with experimental result.

\section{Computational Method}

The newly developed ONIOM method, ${ }^{12}$ implemented in the Gaussian $03^{13}$ package, allowed us to perform high level theoretical calculations in bulk system. In this work, we have adopted a two-layered ONIOM method - inner layer for the most critical elements of the system and outer layer for the rest of the system. The total ONIOM energy $E^{O N O H A}$ is given by

$$
E^{\text {ONIOM }}=E_{\text {hroclet }}^{\text {tigh }}+E_{\text {reul }}^{\text {tow }}-E_{\text {model }}^{\text {tow }}
$$

where $E_{\text {moted }}^{\text {figh }}$ is the energy of the inner layer at the high level of theory, $E_{\text {real }}^{\text {ool }}$ is the energy of the entire system at the low level of theory, and $E_{\text {moodel }}^{\text {jot }}$ is the energy of the model system at the low level of theory. $E^{\text {NWOAF }}$ includes the interaction between the inner layer and the outer layer, while $E_{\text {tiglt }}^{\text {thigt }}$ only serves to the inner layer. ${ }^{12(9), 14}$ Therefore, $\Delta E^{\text {int }}$ defined as the difference in the activation energies between the entire system and the inner layer $\left(=\Delta E^{O N O M x}-\Delta E_{\text {moted }}^{\text {fight }}\right)$ indicates the stabilization or destabilization by the outer layer. In this work, $\mathrm{HF} / 3-21 \mathrm{G}^{*}$ was chosen as the high level and the semiempirical PM3 method $^{15}$ was selected as the low level.

Acknowledgments. This work was supported by INHA UNIVERSITY Research Grant.

\section{References}

I. Tapia, O.; Lluch, J. M.; Cardenas, R.; Andrest, J. J. Am. Chen. Soc. $1989,11,829$.

2. Jencks, W. P. Catalysis in Chemistry and Enzymology, Dover Publications Inc.: New York, 1987.

3. Eigen, M. Discuss. Faradan Soc. 1965, 39, 7.

4. Huang, H. H.; Robinson, R. R.; Long, F. A. J. Ant. Chent. Soc. $1966,88,1866$.

5. (a) Wolfe, S.; Kim, C. K.; Yang, K.; Weinberg, N.; Shi, Z. J. Am. Chem. Soc. 1995, 117,4240 . (b) Wolfe, S.; Shi, Z.; Yang, K.; Ro, S.; Weinberg, N.; Kim, C. K. Can. J. Chem, 1998, 76, I14. (c) Heieh, Y.-H.; Weinberg, N.; Yang, K.; Kim, C. K.; Shi, Z.; Wolfe, S. Can. J. Chem. 2005, 83, 769. (d) Heieh, Y.-H.; Weinberg, N.; Wolfe, S. Cam. J. Chem. 2008, 86. I.

6. (a) Bell, R. P.; Millington, J. P.; Pink, J. M. Proc. Roy: Soc. A 1968, 303,1 , (b) Bell, R. P.; Sorensen, P. E. J. Chem. Soc. Perkin Trans, II 1972, 1740. (c) Bell, R. P. A\&. Phys. Org. Chem, 1966, 4, I.

7. (a) Pocker, Y., Meany, J. E. J. Phys. Chem, 1967, 7I, 3113. (b) Venkatasubban, K. S.; Bush, M.; Ross, E.; Schultz, M.; Garza, O. J. Org. Chent 1998, 63,6115.

8. (a) Freccero, M.; Valentin, C. D.; Sarzi-Amade, M. J. Am. Chen. Soc. 2003, 125, 3544. (b) Diaz, N.; Suárez, D.; Sordo, T. L. Chem. Eur. J. 1999, 5, 1045. (c) Diaz, N.; Suárez, D.; Sordo, T. L. J. Am. Chem. Soc. 2000, 122,6710 .

9. Connolly, M. L. J. Appl. Cryst. 1983, J6, 548.

10. MS Modeling; Accelrys Inc.: San Diego, U.S.A.

11. (a) Zavitsas, A. A.; Coffiner, M.; Wiseman, T.; Zavitsas, L. R. J. Phys, Chem. 1970, 74, 2746. (b) Williams, I. H.; Spangler, D.; Femec, D. A.; Maggiora, G. M.; Schowen, R. L. J. Am. Chem. Soc. 1983, 105, 31.

12. (a) Maseras, F.; Morokuma, K. J. Contut. Chem. 1995, $/ 6,1170$. (b) Humbel, S.; Sieber, S.; Morokuma, K. J. Chem. Phss, 1996, 105, 1959. (c) Svensson, M.; Humbel, S.; Froese, R. D. J.; Matsubara, T.; Sieber, S. N.; Morokuma, K. J. Phys, Chem. 1996, 100, 19357. (d) Dapprich, S.; Komaromi, I.; Byun, K. S.; Morokuma, K.; Frisch, M. J. J. Mol. Strict. (Theochem) 1999, 461, I.

13. Frisch, M. J.; Trucks, G. W.; Schlegel, H. B.; Scuseria, G. E.; Robb, M. A.; Cheeseman, J. R; Montgomery, J. A.; Vreven, Jr., T.; Kudin, K. N.; Burant, J. C.; Millam, J. M.; Jyengar, S. S.; Tomasi, J.; Barone, V.; Mennucci, B.; Cossi, M.; Scalmani, G.; Rega, N.; Petersson, G. A.; Nakalsuji, H.; Hada, M.; Ehara, M.; Toyola, K.; Fukuda, R.; Hasegawa, J.; Ishida, M.; Nakajima, T.; Honda, Y.; Kitao, O.; Nakai, H.; Klene, M.; Li, X.; Knox, J. E.; Hratchian, H. P.; Cross, J. B.; Adamo, C.; Jaramillo, J.; Gomperts, R.; Stratmann, R. E.; Yazyev, O.; Austin, A. J.; Cammi, R.; Pomelli, C.; Ochterski, J. W.; Ayala, P. Y.; Morokuma, K,; Voth, G. A.; Salvador, P.; Dannenberg, J. J.; Zakrzewski, V. G; Dapprich, S.; Daniels, A. D.; Strain, M. C.; Farkas, O.; Malick, D. K.; Rabuck, A. D.; Raghavachari, K.; Foresman, J. B.; Ortiz, J. V.; Cui, Q.; Baboul, A. G.; Clifford, S.; Cioslowski, J.; Stefanov, B. B.; Liu, G.; Liashenko, A.; Piskorz, P.; Komaromi, I.; Martin, R. L.; Fox, D. J.; Keith, T.; Al-Laham, M. A.; Peng, C. Y,; Nanayakkara, A.; Challacombe, M.; Gill, P. M. W.; Johnson, B.; Chen, W; Wong, M. W.; Gonzalez, C.; Pople, J. A. Gaussian 03, Revision B.03; Gaussian, Inc.: Pittsburgh, PA, 2003.

14. Sklenak, S.; Yao, L.; Cukier, R. I.; Yan, H. J. An. Chem. Soc. 2004. 126,14879 .

15. (a) Stewart, J. J. P. J. Comput, Chem. 1989, 10, 209. (b) Stewart, J. J. P. J. Comput. Chem. 1989, 10, 221. 